Published in final edited form as:

Cochrane Database Syst Rev. 2014 November ; 2014(11): . doi:10.1002/14651858.CD011366.

\title{
Combination medical treatment for primary open angle glaucoma and ocular hypertension: a network meta-analysis
}

\author{
Manuele Michelessi ${ }^{1,2}$, Kristina Lindsley ${ }^{2}$, Tsung $\mathbf{Y u}^{2}$, and Tianjing $\mathbf{L i}^{2}$ \\ ${ }^{1}$ Ophthalmology, Fondazione G.B. Bietti per lo studio e la ricerca in Oftalmolologia-IRCCS, \\ Rome, Italy. \\ 2Department of Epidemiology, Johns Hopkins Bloomberg School of Public Health, Baltimore, \\ Maryland, USA
}

\begin{abstract}
This is the protocol for a review and there is no abstract. The objectives are as follows:

The objectives of this review are to examine the comparative effectiveness and safety of different glaucoma fixed combination therapies and monotherapies in eyes with primary open angle glaucoma or ocular hypertension and to provide relative rankings of these treatments.
\end{abstract}

\section{BACKGROUND}

\section{Description of the condition}

Glaucoma is a chronic neurodegenerative condition characterized by a loss of retinal ganglion cells and their axons. These neurode-generative changes lead to optic nerve head $(\mathrm{ONH})$ and retinal nerve fiber layer (RNFL) damage and are associated with visual field (VF) defects (Weinreb 2004). Based upon the appearance of the anterior chamber angle, glaucoma is classified as open angle glaucoma (OAG) in which the trabecular meshwork is clearly visible during the clinical examination by gonioscopy, or angle closure glaucoma in which the iris blocks the drainage angle through iridotrabecular contact and the gonioscopic view of the trabecular meshwork consequently is blocked for at least 180 degrees (AAO 2010). Both diagnoses are further classified into a primary (i.e., idiopathic) form or a secondary form in which glaucoma is associated with accountable comorbidity, such as uveitis, rubeosis caused by ocular ischemia, pseudoexfoliation, pigmentary dispersion syndrome or any ocular surgery (King 2013). Primary open angle glaucoma (POAG) is the most common type, accounting for about $70 \%$ of glaucoma cases.

Copyright $\odot 2014$ The Cochrane Collaboration. Published by John Wiley \& Sons, Ltd.

Contact address: Manuele Michelessi, Ophthalmology, Fondazione G.B. Bietti per lo studio e la ricerca in Oftalmolologia-IRCCS, Via Livenza n 3, Rome, 00198, Italy. manuele_michelessi@yahoo.it.mmichele@jhsph.edu..

CONTRIBUTIONS OF AUTHORS

MM wrote the protocol draft. KL, TY, and TL provided substantive comments and edits to the protocol. All authors approved the final version of the protocol.

DECLARATIONS OF INTEREST

None known. 
Epidemiology - Glaucoma is a leading cause of irreversible blindness worldwide with approximately 60.4 million people affected in 2010 (Quigley 2006). This number is expected to increase to 79 million in 2020 with 11.1 million people bilaterally blind from the condition (Quigley 2006). The incidence of OAG is strongly correlated to age and ethnicity. As population studies have shown, the incidence of OAG varies from $0.35 \%$ (95\% confidence interval (CI) 0.29 to 0.44 ) per year in non-Hispanic whites (de Voogd 2005), to $0.49 \%$ (95\% CI 0.41 to 0.58 ) per year in African-descent blacks (Leske 2007), and to 0.58\% (95\% CI 0.45 to 0.70 ) per year in Latinos (Varma 2012). Increasing the age of populations considered, increases the incidence of OAG (Varma 2012).

Risk factors for POAG include high intraocular pressure (IOP), older age, family history of glaucoma, low perfusion pressure, African ancestry or Latino ethnicity, thinner central cornea, and myopia (Brandt 2001; Gordon 2002; Marcus 2011; Sommer 1991a; Varma 2004). Although IOP is no longer considered as a diagnostic criterion for glaucoma, it is the only known risk factor that can be modified. Higher IOP is associated with higher risk of ocular structure damage and development of glaucoma (Quigley 2011; Sommer 1991b). Furthermore, reducing IOP has been shown to slow the progression of glaucoma. In the Early Manifest Glaucoma Trial, progression risk was decreased by 10\% with each $1 \mathrm{mmHg}$ of IOP reduction from baseline to the first follow-up visit (Leske 2003). It also has been shown that among glaucoma patients who have reached target IOP (a $\geq 30 \%$ or physiciandefined reduction from baseline), additional IOP reduction ( $220 \%$ ) further reduces the rate of VF changes over time (Chauhan 2010).

Presentation and diagnosis-In most cases, glaucoma progresses gradually over many years. The disease develops and progresses with no symptoms until the very advanced stages, and the diagnosis usually occurs during screening or a visit carried out for other reasons. At the time of diagnosis, a variable amount of visual damage often may have developed already. Without timely diagnosis and appropriate treatment, eyes with glaucoma will progress toward blindness. It has been estimated that a high percentage of glaucoma remains undiagnosed (Weinreb 2004). Traditionally, the diagnosis of glaucoma is based on structural changes to the ONH and RNFL (as assessed subjectively by means of fundus oculi or stereophoto evaluation) and/or on functional visual field defects as assessed by automated perimetry. An IOP outside the normal ranges and a suspected ONH appearance are the conditions that usually require a more in-depth diagnostic assessment.

In healthy eyes, IOP typically ranges between 10 and $21 \mathrm{mmHg}$ (mean $15.5 \mathrm{mmHg}$, standard deviation $2 \mathrm{mmHg}$ ). When glaucoma patients have an untreated IOP less than or equal to $21 \mathrm{mmHg}$, they are referred to as having normal tension glaucoma (NTG). Those patients with an untreated IOP above $21 \mathrm{mmHg}$ are referred to as having high tension glaucoma (HTG) or simply OAG. Both NTG and HTG patients demonstrate some form of $\mathrm{ONH}$ and/or VF damage; consequently, $21 \mathrm{mmHg}$ is an artificial cut off point. Thus, NTG simply represents a different expression of glaucoma (Shields 2008; Sommer 2011). In contrast, ocular hypertension (OHT) refers to individuals with an IOP greater than $21 \mathrm{mmHg}$ but without ONH or VF damage. In some OHT individuals, clinically-detectable glaucomarelated structural damage may never develop (Kass 2002). 


\section{Description of the intervention}

Lowering IOP to delay or prevent ONH and/or VF damage can be achieved by means of medical treatment (Vass 2007), laser procedure (Rolim de Moura 2007), or surgical intervention (Burr 2012). The medical approach, primarily the use of topical pharmaceutical agents, is considered as the first-line treatment (Everitt 1990). Topical pharmaceutical agents can increase the aqueous humor outflow, decrease its production, or act through a combination of both mechanisms (Hurvitz 1991). Currently, five classes of agents are used to lower IOP: prostaglandin analogs, $\beta$-blockers, carbonic anhydrase inhibitors, $\alpha-2$ adrenergic agonists, and parasympathomimetics.

\section{How the intervention might work}

The effectiveness and safety of each class of drug vary among patients. The treatment usually begins with a single drug used alone as a monotherapy. In up to $75 \%$ of glaucoma patients, a monotherapy will fail to control IOP satisfactorily after two years of therapy (Kass 2002). Many patients may require switching to a different drug or adding other drugs from two or more classes to control IOP (AAO 2010; Webers 2008).

Combination therapy requires instilling two or more eye drops several times a day. Increasing the number of daily instillations reduces the ability of patients to adhere to prescribed therapy (Djafari 2009), whereas simplifying drop regimens may be beneficial to improve patients' satisfaction and adherence (Waterman 2013). Complex therapeutic regimens also are associated with additional side effects due to the amount of preservatives included in each drop instilled (Baratz 2006). Further, when two drops are instilled too close in time, the application of the second drug may reduce the effect of the first drug (Sleath 2006). To overcome these potential problems, fixed combination (FC) therapy, in which two different drugs are mixed in the same bottle and instilled together in the same drop, was introduced (Fechtner 2004).

The first FC eye drop was a combination of pilocarpine and epinephrine or betaxolol. This form of $\mathrm{FC}$ is no longer in use due to the unfavorable safety profile of pilocarpine (e.g., blurred vision, reduced night vision). Most commonly used FCs nowadays combine timolol with either a carbonic anhydrase inhibitor (dorzolamide or brinzolamide), a prostaglandin analog (travoprost, bimatoprost or latanoprost), or an $\alpha$-2 agonist (brimonidine). A triple combination of timolol with both a carbonic anhydrase inhibitor (dorzolamide) and an $a-2$ agonist (brimonidine) also is available. In the United States (US), only three FC eye drops are approved by the Food and Drug Administration (FDA): timolol-dorzolamide FC (approved in 1998), timolol-brimonidine FC (approved in 2007), and brimonidinebrinzolamide (approved in 2013). FCs of timolol plus brinzolamide or plus one of three prostaglandin analogs (latanoprost, travoprost or bimatoprost) are not available in the US but have been approved and are widely used in Europe.

Although FC therapy means at least two drugs are instilled instead of one, it may not always require more drops per day. The number of instillations depends on the drugs involved (e.g., when switching from timolol twice per day to bimatoprost plus timolol once per day, one instillation per day is omitted). The effects of such change of therapy are not clearly 
understood. Moreover, although the multi-therapeutic regimen theoretically should be more effective than monotherapy alone and the FC option is being used more and more frequently in clinical practice as second-line therapy, its comparative effectiveness with monotherapy has not been established unequivocally (Bron 2002; Webers 2007).

\section{Why it is important to do this review}

Ophthalmologists often need to adjust an ineffective or unsatisfactory monotherapy; thus, they are faced with a decision whether to try an alternative monotherapy or to switch to a multi-therapy, usually represented by an FC therapy. In addition, there are a number of FC therapies from which ophthalmologists and patients can choose. A standard meta-analysis that focuses on a pairwise comparison, that is evaluation of one FC option at a time, will not be able to answer the question of the comparative effectiveness and safety of all treatment options. In this systematic review, we will use network meta-analysis, a statistical technique to facilitate "all-way" comparisons. Network meta-analysis combines evidence within trials ("direct evidence") and evidence across trials ("indirect evidence") (Li 2011). Treatment effects estimated from network meta-analyses usually have improved precision and inferences can be made even for treatments not directly evaluated in individual trials. Through a network meta-analysis, one can also obtain relative rankings for multiple competing treatments. We will conduct a systematic review and network meta-analysis of evidence from randomized controlled trials (RCTs) on this topic to provide a better understanding of what works best to preserve the patient's vision over time in this patient population.

\section{OBJECTIVES}

The objectives of this review are to examine the comparative effectiveness and safety of different glaucoma fixed combination therapies and monotherapies in eyes with primary open angle glaucoma or ocular hypertension and to provide relative rankings of these treatments.

\section{METHODS}

\section{Criteria for considering studies for this review}

Types of studies-We will include only RCTs in this review.

Types of participants-We will include RCTs that enrolled adult participants (18 years or older) with primary open angle glaucoma (POAG) or ocular hypertension (OHT). We will not include RCTs that evaluated only participants with a secondary form of glaucoma, such as pigmentary or pseudoexfoliative glaucoma.

Monotherapy is the typical first-line treatment, but participants at an advanced stage of disease when first diagnosed may require more aggressive therapy (e.g., combination therapy) as the first treatment. Therefore, we will include RCTs in which participants were receiving some form of drug treatment at the time of study enrollment, as well as RCTS in which participants had never been treated. We will not restrict any studies with regard to gender, ethnicity or comorbidity. We expected that POAG and OHT definition criteria vary 
considerably across different studies, with various combinations of diagnostic criteria for intraocular pressure (IOP), visual field (VF) and optic nerve head (ONH) damages. We will accept any POAG and OHT definitions as used in the RCTs. We will accept any stage of the disease, with no restriction in any direction (very early stages as well as more advanced stages).

Types of interventions-We will consider RCTs that compared the following FC therapies and monotherapies in any combination for the intent of lowering IOP. We will include multi-arm RCTs. All included interventions are considered to be "jointly randomizable", satisfying the assumption for network meta-analysis (see more details under "Evaluating the assumption for network meta-analysis").

FC therapies:

- Pilocarpine plus epinephrine or betaxolol

- Timolol plus a carbonic anhydrase inhibitor (dorzolamide or brinzolamide)

- Timolol plus a prostaglandin analog (bimatoprost, travoprost, or latanoprost)

- Timolol plus brimonidine

- Brinzolamide plus brimonidine

- Timolol plus dorzolamide and brimonidine

Monotherapies:

- Parasympathomimetics (e.g., pilocarpine)

- $\quad \beta$-blockers (e.g., betaxolol, carteolol, levobunolol, timolol)

- Carbonic anhydrase inhibitor (e.g., brinzolamide)

- $\quad a-2$ adrenergic agonist (e.g., brimonidine)

- Prostaglandin analogs (e.g., bimatoprost, travoprost, latanoprost)

\section{Types of outcome measures}

Primary outcomes-The primary outcome of the review will be change in VF from baseline measured as mean deviation using any perimetry device. The primary end point will be 12 months (range $>8$ to $\leq 12$ months).

\section{Secondary outcomes}

1. Change in VF from baseline measured as mean deviation at 3 months (range $>2$ to $\leq 4$ months), 6 months (range $>4$ to $\leq 8$ months) and $>12$ months (the longest follow-up time point).

2. Change in VF from baseline measured as pattern standard deviation or VF index at 3 months (range $>2$ to $\leq 4$ months), 6 months (range $>4$ to $\leq 8$ months), 12 months (range $>8$ to $\leq 12$ months), and $>12$ months (the longest follow-up time point). 
We also will evaluate the mean value of VF (measured as mean deviation, pattern standard deviation or VF index) at each follow-up time point when available.

3. Mean change in IOP from baseline at 3 months (range $>2$ to $\leq 4$ months), 6 months (range $>4$ to $\leq 8$ months), 12 months (range $>8$ to $\leq 12$ months), and $>12$ months (the longest follow-up time point). We also will evaluate the IOP absolute mean value at each time point whenever it is available.

4. Change in best corrected visual acuity (BCVA) from baseline at 3 months (range > 2 to $\leq 4$ months), 6 months (range $>4$ to $\leq 8$ months), 12 months (range $>8$ to $\leq 12$ months), and $>12$ months (the longest follow-up time point). We also will evaluate the BCVA absolute mean value at each time point, when it is available.

5. ONH/retinal nerve fiber layer (RNFL) damage progression evidence (present or absent), according to the criteria defined in the methodology of each study, at 3 months (range $>2$ to $\leq 4$ months), 6 months (range $>4$ to $\leq 8$ months), 12 months (range $>8$ to $\leq 12$ months), and $>12$ months (the longest follow-up time point).

6. Vision-related quality of life and adherence data, according to the criteria defined in each study, at 12 months.

Adverse outcomes-We will evaluate the following adverse outcomes: infection, inflammation and local adverse outcomes such as burning, redness, eye irritation, ocular pain, tearing, and discomfort. We will evaluate systemic adverse outcomes including chronic cardiovascular or pulmonary obstructive complication. Because the adverse outcome profiles for different classes of glaucoma medications are different, we will tabulate and analyze the above listed adverse events instead of designating one as the primary adverse outcome. We anticipate that most of the adverse events will be reported as binary data (e.g., number of participants with events) or number of events (e.g., number of events occurred altogether). We will choose the measure of association appropriate for the data type.

Economic data-We will not consider economic data in this review.

\section{Search methods for identification of studies}

Electronic searches-We will search the Cochrane Register for Controlled Trials (CENTRAL) (which contains the Cochrane Eye and Vision Group Trials Register) (latest issue), Ovid MEDLINE, Ovid MEDLINE In-Process and Other Non-Indexed Citations, Ovid MEDLINE Daily, Ovid OLDMEDLINE (January 1946 to present), EM-BASE (January 1980 to present), PubMed (1948 to present), the metaRegister of Controlled Trials ( $m$ RCT) (www.controlled-trials.com), ClinicalTrials.gov (www.clinicaltrials.gov) and the World Health Organization (WHO) International Clinical Trials Registry Platform (ICTRP) (www.who.int/ictrp/search/en). We will not use any date or language restrictions in the electronic search for trials.

See: Appendices for details of search strategies for CENTRAL (Appendix 1), MEDLINE (Appendix 2), EMBASE (Appendix 3), PubMed (Appendix 4), $m$ RCT (Appendix 5), ClinicalTrials.gov (Appendix 6) and the ICTRP (Appendix 7). 
Searching other resources-We will search the references of included studies to identify additional studies that could be included. We will search the FDA and European Medicine Agency websites for RCTs submitted for regulatory approval.

\section{Data collection and analysis}

Selection of studies-Two review authors independently will assess the titles and abstracts of all studies identified by the electronic and manual searches. We will label each record at this stage as "definitely relevant," "possibly relevant" or "definitely not relevant." We will exclude records labeled as "definitely not relevant" by both review authors. We will retrieve full-text reports of records labeled as "definitely relevant" or "possibly relevant" and two review authors independently will assess whether they meet the inclusion criteria. We will resolve any disagreement when present at any stage through discussion. When necessary, we will consult a third review author or contact the study investigators for more information to determine eligibility.

Data extraction and management-Two review authors independently will extract data related to study design and methods, participant characteristics, interventions, and outcomes using an electronic form developed and maintained in the Systematic Review Data Repository (SRDR, srdr.ahrq.gov). We will compare data extracted by the two review authors and resolve discrepancies by discussion or, when necessary, by consulting a third review author. One review author will enter data into RevMan 5.3 (Revman 2014) and a second review author will verify the data entered.

Assessment of risk of bias in included studies-Two review authors will evaluate the following domains for risk of bias: sequence generation and allocation sequence concealment (selection bias), masking of participants (performance bias) and outcome assessors (detection bias), incomplete outcome data (attrition bias), selective outcome reporting (reporting bias), and other potential sources of bias. We will evaluate each study and assign for each 'Risk of bias' domain a judgment of "low risk of bias," "high risk of bias" or "unclear risk of bias" following criteria outlined in Chapter 8 of the Cochrane Handbook for Systematic Reviews of Interventions (Higgins 2011). We will resolve discrepancies by discussion or, when necessary, by consulting a third review author or by contacting the study investigators for more information. If we do not receive a response from study investigators within six weeks, we will use the information available in published reports to judge the risk of bias.

Measures of treatment effect-We will calculate mean differences with $95 \%$ confidence intervals (CIs) for continuous outcomes, including the primary outcome and secondary outcomes \#1 to 4 . For dichotomous outcomes (ONH/RNFL damage progression evidence and adverse events), we will use summary risk ratios with $95 \%$ CIs. We will generate probabilities of each treatment taking each possible rank and the cumulative ranking probabilities, known as "sucra" plots (Chaimani 2013; Salanti 2011). Sucra plots show the relative probability of each intervention being among the best treatment options. 
Unit of analysis issues-We expect that a majority of trials will have randomized either individual participants or one eye per participant. In this case, the unit of analysis will be individual participant. When two eyes of the same participant have been randomized independently, we will use appropriate estimates from the trial report that accounted for inter-eye correlation of measurements and outcomes between the two eyes of each participant. Because we plan to conduct network meta-analyses, we will account for the correlation among arms within multi-arm trials (see details under Data synthesis).

Dealing with missing data-We will contact study investigators in an attempt to obtain missing data. We will use available information when we do not receive an answer within six weeks. We will not impute missing data.

Assessment of heterogeneity-We will evaluate clinical, methodological and statistical heterogeneity. We will assess participant characteristics, interventions and outcomes as well as study design and risk of bias, to assess clinical and methodological heterogeneity. We will use the $\mathrm{I}^{2}$ and tau ${ }^{2}$ values, and Q statistics test to quantify the statistical heterogeneity. We will consider $\mathrm{I}^{2}>75 \%$ as the cut-off point to identify the presence of considerable heterogeneity.

Evaluating the assumption for network meta-analysis-The consistency assumption of network meta-analysis implies that participants included in the network could hypothetically be randomized to any of the interventions represented in the network (Salanti 2012). Interventions defined in our review are comparable in that any of them could theoretically be chosen as a treatment modality for POAG/OHT participants who were receiving some form of drug treatment or presented with advanced stage of disease at the time of study enrollment. We will use our qualitative assessment (i.e., evaluation of participant characteristics, interventions, outcomes, and design characteristics) to inform the assessment of consistency assumption. We will compare the distributions of characteristics that may modify the treatment effect.

We will further evaluate statistical disagreement of direct and indirect evidence, known as inconsistency, by a loop-specific approach and by fitting design-by-treatment interaction models (Dias 2013; Jackson 2014; White 2011; White 2012). We will fit an inconsistency network meta-analysis model when statistical inconsistency is present and cannot be explained.

We will conduct network meta-analysis using a suite of "network" commands in STATA 13® (Stata 2013).

Assessment of reporting biases-When a sufficient number of studies is included (10 or more), we will assess the evidence of reporting bias by examining asymmetry in the funnel plot of effect estimates. We will check whether the trials submitted to the FDA have been published; if so, we will compare outcome data between the FDA documents and the study publications. 
Data synthesis-When no substantial clinical and methodological heterogeneity is present (as defined above in Assessment of heterogeneity), we first will conduct pair-wise meta-analyses for all direct comparisons using a random effects model. We will assume comparison-specific statistical heterogeneity (i.e., each pair-wise meta-analysis will have a separate estimate of statistical heterogeneity) as well as a common heterogeneity across all comparisons (i.e., all pair-wise meta-analyses will have a common estimate of statistical heterogeneity). We then will fit network meta-analysis models using the multivariate metaregression approach proposed by White et al (Jackson 2014; White 2011; White 2012). This model also handles multi-arm trials. We will report direct estimates of treatment effects and estimates from the network meta-analysis.

\section{Subgroup analysis and investigation of heterogeneity and inconsistency-}

When sufficient data are available we will conduct subgroup analyses by diagnosis (POAG versus OHT), baseline mean IOP level $(<24 \mathrm{mmHg}$ versus $22 \mathrm{mmHg}$ ), baseline treatment status (treatment 'naive' versus prior glaucoma treatment) and classes of drugs. We will conduct subgroup analysis only for the primary outcome.

Sensitivity analysis-We will conduct a sensitivity analysis to evaluate the effect of excluding studies judged as having a high risk of bias on allocation concealment. We also will conduct a sensitivity analysis excluding studies sponsored by drug companies.

'Summary of findings'-When data are available, we will include 'Summary of findings' tables, according to methods described in Chapters 11 and 12 of the Cochrane Handbook for Systematic Reviews of Interventions (Schünemann 2011a; Schünemann 2011b), for the following outcomes:

1. Mean change in $\mathrm{VF}$ from baseline measured as mean deviation using any perimetry device.

2. Mean change in VF from baseline measured as pattern standard deviation or VF index.

3. Mean change in IOP from baseline.

4. Mean change in BCVA from baseline.

5. Proportion with $\mathrm{ONH} / \mathrm{RNFL}$ damage progression present, according to the criteria defined in the methodology of each study.

6. Proportion with total adverse outcomes.

7. Proportion with systemic adverse outcomes including chronic cardiovascular or pulmonary obstructive complication. We do not plan to apply the GRADE approach to assessing the strength of evidence (Puhan 2014).

\section{ACKNOWLEDGEMENTS}

We acknowledge the Cochrane Eyes and Vision Group (CEVG) for creating and executing the electronic search strategies. We thank Anna Chaimani, Gregory Katz, and Barbara Hawkins for providing peer review comments for this protocol. 
SOURCES OF SUPPORT

Internal sources

- $\quad$ No sources of support supplied

External sources

- $\quad$ National Eye Institute, National Institutes of Health, USA.

Kristina Lindsley, Tsung Yu, Tianjing Li supported by Grant 1 U01 EY020522

- $\quad$ National Institute for Health Research (NIHR), UK.

- $\quad$ Richard Wormald, Co-ordinating Editor for the Cochrane Eyes and Vision Group (CEVG) acknowledges financial support for his CEVG research sessions from the Department of Health through the award made by the National Institute for Health Research to Moorfields Eye Hospital NHS Foundation Trust and UCL Institute of Ophthalmology for a Specialist Biomedical Research Centre for Ophthalmology.

- The NIHR also funds the CEVG Editorial Base in London.

The views expressed in this publication are those of the authors and not necessarily those of the NIHR, NHS, or the Department of Health.

\section{APPENDICES}

\section{Appendix 1. CENTRAL search strategy}

\#1 MeSH descriptor: [Glaucoma, Open-Angle] explode all trees

\#2 MeSH descriptor: [Ocular Hypertension] explode all trees

\#3 (open near/2 angle near/2 glaucoma*)

\#4 (POAG or OHT)

\#5 (((increas* or elevat* or high*) near/3 (ocular or intra-ocular)) and pressure)

$\# 6\{$ or \#1-\#5\}

\#7 MeSH descriptor: [Adrenergic beta-Antagonists] explode all trees

\#8 ((Adrenergic near/1 beta* near/3 Blocker*) or (Adrenergic near/1 beta* near/3

Blockader*) or (beta* near/1 Adrenergic near/3 Blocking near/3 Agent*) or (Adrenergic near/1 beta* near/3 Antagonist*) or (beta* near/1 Adrenergic near/3 Blocking near/3 drug*) or (beta* near/2 antagonist*) or (beta* near/2 blocker*) or (beta* near/3 blocking near/2 agent*) or (beta near/3 blocking near/2 drug*) or Beta* antiadrenergic agent* or beta* sympathicolytic* or beta* sympatholytic*)

\#9 MeSH descriptor: [Timolol] explode all trees

\#10 (Timolol* or Timoptic or Timoptol or Timacar or L-714,465 or L714465 or MK-950 or MK950 or Optimol or Blocadren or 26839-75-8)

\#11 MeSH descriptor: [Metipranolol] explode all trees \#12 (Metipranolol* or Methypranol or Trimepranol or Disorat or 22664-55-7) 
\#13 MeSH descriptor: [Carteolol] explode all trees

\#14 (Carteolol* or OPC-1085 or OPC1085 or 51781-06-7)

\#15 MeSH descriptor: [Levobunolol] explode all trees

\#16 (Levobunolol* or PMS-Levobunolol or PMSLevobunolol or ratio-Levobunolol or Ultracortenol or Vistagan or W-6412A or W6412A or AKBeta or Apo-Levobunolol or ApoLevobunolol or Betagan or Bunolol or Novo-Levobunolol or NovoLevobunolol or W-7000A or W7000A or 47141-42-4)

\#17 MeSH descriptor: [Betaxolol] explode all trees

\#18 (Betaxolol* or Kerlone or Kerlon or Oxodal or SL-75212 or SL75212 or ALO-1401-02 or ALO140102 or Betoptic or Betoptima or 63659-18-7)

\#19 MeSH descriptor: [Carbonic Anhydrase Inhibitors] explode all trees

\#20 ((Carbonic near/2 Anhydrase near/2 Inhibitor*) or (Carbonate near/2 Dehydratase near/2 Inhibitor*) or (Carboxyanhydrase near/ 1 Inhibitor*))

\#21 MeSH descriptor: [Acetazolamide] explode all trees

\#22 (Acetazolam* or Ak-Zol or AkZol or Apo-Acetazolamide or ApoAcetazolamide or Diacarb or Diamox or Diuramide or Defiltran or Edemox or Glauconox or Glaupax or Huma-Zolamide or HumaZolamide or Acetadiazol or azetazolamide* or 59-66-5)

\#23 (Brinzolamide* or Azopt or 138890-62-7)

\#24 (Dorzolamide* or MK-507 or Trusopt or L-671152 or 130693-82-2)

\#25 MeSH descriptor: [Prostaglandins, Synthetic] explode all trees

\#26 (“Synthetic Prostaglandins" or "PG Analogs" or "Prostaglandin Analogues" or

"Prostaglandin Analogs" or dimethylprostaglandin or methylprostaglandin or "prostaglandin 1 ")

\#27 (latanoprost* or PHXA41 or Xalatan or PhXA34 or 130209-82-4)

\#28 (travoprost* or Travatan or AL-6221 or AL6221 or 157283-68-6)

\#29 (bimatoprost* or latisse or Lumigan or AGN192024)

\#30 (unoprostone* or UF-021 or Rescula or Eescula or 69553-75-9)

\#31 (tafluprost* or "AFP 168" or AFP168 or "de 085 " or de 085 or taflotan or tapros or zioptan or 209860-87-7)

\#32 MeSH descriptor: [Antihypertensive Agents] explode all trees \#33 (antihypertensive* or "Anti Hypertensives” or “Anti Hypertensive”) 
\#34 MeSH descriptor: [Pilocarpine] explode all trees

\#35 (Pilocarpin* or Isoptocarpine or Salagen or Isopilocarpine or Ocusert or adsorbocarpine or akarpine or almocarpine or asthenopin or glaucocarpine or "isopto carpine" or isoptopilocarpine or liocarpina or miocarpine or ocu-carpine or ocucarpine or pilagan or pilasite or pilocar or pilocarpin or pilocarpol or pilofrin or pilogel or piloheptine or pilomann or pilomin or pilomiotin or pilopine or pilostat or pilosyst or pilotonina or sanpilo or "sno pilo" or spersacarpine or vistacarpin or vitacarpine or zhenrui or 148-72-1 or 54-71-7 or 92-13-7)

\#36 MeSH descriptor: [Epinephrine] explode all trees

\#37 (epinephrine* or adrenalin* or Medihaler-Epi or Epitrate or Lyophrin or Epifrin or Adnephrin* or adrenamine or adrenapax or adrenazin or adrenine or adrin or adrine or advaradin or anapen or asthmahaler or balmadren or biorenine or bosmin or chelafrin or dylephrin or epimephrine or epinefrina or epinephran or epinephrin* or epipen or epirenamine or epirenan or exadrin or glaucon or glaucosan or glaufrin or glycirenan or haemostatin or hemisine or hemostasin or hemostatin or hypernephrin or "isopto epinal" or 1-adrenalin or levoepinephrine or levorenin* or methylaminoethanolcatechol or methylarterenol or mucidrina or myosthenine or nephridine or nieraline or paranephrin or posumin or "primatene mist" or renaglandin or renaleptine or renalina or renaline or renoform or renostypticin or renostyptin or scurenaline or simplene or soladren or sphygmogenin or supracapsulin or supranephrin or supranol or suprarenaline or suprarenin* or suprel or surenine or surrenine or sus-phrine or susphrine or takamina or tonogen or trenamist or twinject or vasoconstrictine or vasodrine or vasotonin or weradren or 51-43-4 or $55-31-2)$

\#38 (dipivefrin* or dipivaloylepinephrine or Dipoquin or Glaucothil or Glaudrops or PMSDipivefrin or Propine or Diopine or ratio-Dipivefrin or Apo-Dipivefrin or 52365-63-6 or 56298-24-9)

\#39 MeSH descriptor: [Adrenergic alpha-2 Receptor Agonists] explode all trees \#40 ((adrenergic near/2 alpha* near/3 agonist*) or (alpha* near/2 adrenergic near/3 agent*) or (alpha* near/2 adrenergic receptor) or (alpha* near/2 adrenergic near/2 stimula*) or (alpha* near/2 adrenoceptor near/2 stimula*) or (alpha* near/3 agonist) or alpha* sympathicomimetic or noradrenalin agonist* or noradrenergic agonist* or noradrenergic receptor stimulating agent*)

\#41 (apraclonidin* or para-aminoclonidine or p-aminoclonidine or Iopidine or Iopimax or "ALO 2145" or "4 aminoclonidine" or aplonidine or clonidine or "4 amino" or iopidine or lapidine or 66711-21-5)

\#42 (brimonidine* or bromoxidine or ratio-Brimonidine or Alphagan or UK-14,308 or UK-14304 or UK-14304-18 or AGN-190342 or 59803-98-4) \#43 (drug* or medic* or pharmacologic*) near/3 (treat* or therap* or intervent*) 


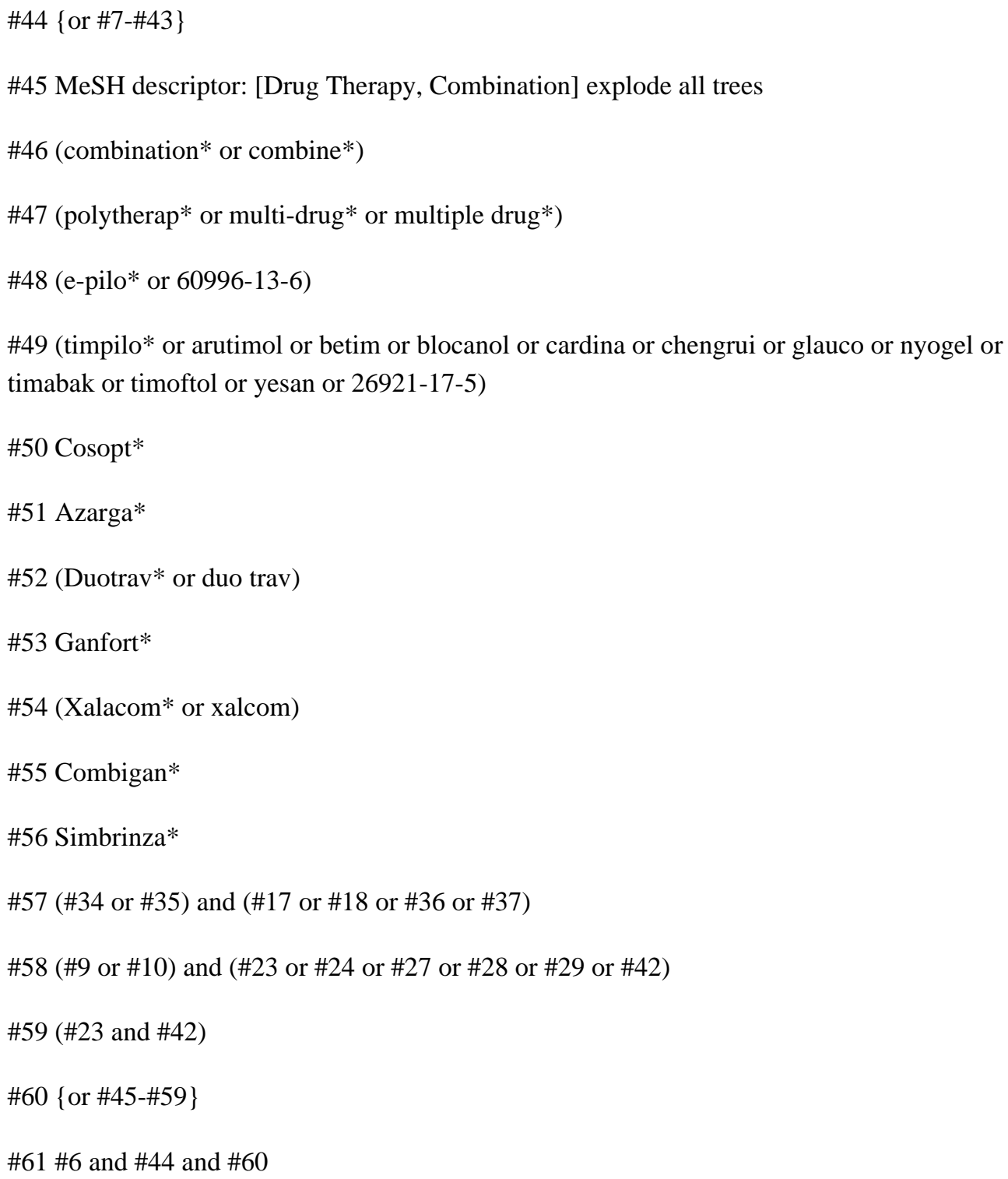

\section{Appendix 2. MEDLINE (OvidSP) search strategy}

1. exp clinical trial/

2. (randomized or randomised).ab,ti.

3. placebo.ab,ti.

4. drug therapy.fs.

5. randomly.ab,ti.

6. trial.ab,ti.

7. groups.ab,ti.

8. 1 or 2 or 3 or 4 or 5 or 6 or 7 
9. exp animals/ not humans.sh.

10. 8 not 9

11. exp glaucoma open angle/

12. exp ocular hypertension/

13. (open adj2 angle adj2 glaucoma\$).tw.

14. (POAG or OHT).tw.

15. (((increas $\$$ or elevat $\$$ or high $\$)$ adj3 (ocular or intra-ocular)) and pressure).tw.

16. or/11-15

17. exp adrenergic beta antagonists/

18. ((Adrenergic adj1 beta* adj3 Blocker*) or (Adrenergic adj1 beta* adj3 Blockader*) or (beta* adj1 Adrenergic adj3 Blocking adj3 Agent*) or (Adrenergic adj1 beta* adj3 Antagonist*) or (beta* adj1 Adrenergic adj3 Blocking adj3 drug*) or (beta* adj2 antagonist*) or (beta* adj2 blocker*) or (beta* adj3 blocking adj2 agent*) or (beta adj3 blocking adj2 drug*) or Beta* antiadrenergic agent* or beta* sympathicolytic* or beta* sympatholytic*).tw.

19. exp timolol/

20. (Timolol* or Timoptic or Timoptol or Timacar or L-714,465 or L714465 or MK-950 or MK950 or Optimol or Blocadren or 26839-75-8).tw.

21. exp metipranolol/

22. (Metipranolol* or Methypranol or Trimepranol or Disorat or 22664-55-7).tw.

23. exp carteolol/

24. (Carteolol* or OPC-1085 or OPC1085 or 51781-06-7).tw.

25. exp levobunolol/

26. (Levobunolol* or PMS-Levobunolol or PMSLevobunolol or ratio-Levobunolol or Ultracortenol or Vistagan or W-6412A or W6412A or AKBeta or ApoLevobunolol or ApoLevobunolol or Betagan or Bunolol or Novo-Levobunolol or NovoLevobunolol or W-7000A or W7000A or 47141-42-4).tw.

27. exp betaxolol/

28. (Betaxolol* or Kerlone or Kerlon or Oxodal or SL-75212 or SL75212 or ALO-1401-02 or ALO140102 or Betoptic or Betoptima or 63659-18-7).tw.

29. exp carbonic anhydrase inhibitors/

30. ((Carbonic adj2 Anhydrase adj2 Inhibitor*) or (Carbonate adj2 Dehydratase adj2 Inhibitor*) or (Carboxyanhydrase adj1 Inhibitor*)).tw.

31. exp Acetazolamide/ 
32. (Acetazolam* or Ak-Zol or AkZol or Apo-Acetazolamide or ApoAcetazolamide or Diacarb or Diamox or Diuramide or Defiltran or Edemox or Glauconox or Glaupax or Huma-Zolamide or HumaZolamide or Acetadiazol or azetazolamide* or 59-66-5).tw.

33. Brinzolamide.rn.

34. (Brinzolamide* or Azopt or 138890-62-7).tw.

35. Dorzolamide.rn.

36. (Dorzolamide* or MK-507 or Trusopt or L-671152 or 130693-82-2).tw.

37. exp Prostaglandins, Synthetic/

38. ("Synthetic Prostaglandins" or "PG Analogs" or "Prostaglandin Analogues" or "Prostaglandin Analogs" or dimethylprostaglandin or methylprostaglandin or "prostaglandin 1").tw.

39. latanoprost.rn.

40. (latanoprost* or PHXA41 or Xalatan or PhXA34 or 130209-82-4).tw.

41. travoprost.rn.

42. (travoprost* or Travatan or AL-6221 or AL6221 or 157283-68-6).tw.

43. bimatoprost.rn.

44. (bimatoprost* or latisse or Lumigan or AGN192024).tw.

45. isopropyl unoprostone.rn.

46. (unoprostone* or UF-021 or Rescula or Eescula or 69553-75-9).tw.

47. tafluprost.rn.

48. (tafluprost* or "AFP 168 " or AFP168 or "de 085 " or de 085 or taflotan or tapros or zioptan or 209860-87-7).tw.

49. exp antihypertensive agents/

50. (antihypertensive* or "Anti Hypertensives" or "Anti Hypertensive").tw.

51. exp pilocarpine/

52. (Pilocarpin* or Isoptocarpine or Salagen or Isopilocarpine or Ocusert or adsorbocarpine or akarpine or almocarpine or asthenopin or glaucocarpine or "isopto carpine" or isoptopilocarpine or liocarpina or miocarpine or ocu-carpine or ocucarpine or pilagan or pilasite or pilocar or pilocarpin or pilocarpol or pilofrin or pilogel or piloheptine or pilomann or pilomin or pilomiotin or pilopine or pilostat or pilosyst or pilotonina or sanpilo or "sno pilo" or spersacarpine or vistacarpin or vitacarpine or zhenrui or 148-72-1 or 54-71-7 or 92-13-7).tw.

53. exp epinephrine/

54. (epinephrine* or adrenalin* or Medihaler-Epi or Epitrate or Lyophrin or Epifrin or Adnephrin* or adrenamine or adrenapax or adrenazin or adrenine or adrin or adrine 
or advaradin or anapen or asthmahaler or balmadren or biorenine or bosmin or chelafrin or dylephrin or epimephrine or epinefrina or epinephran or epinephrin* or epipen or epirenamine or epirenan or exadrin or glaucon or glaucosan or glaufrin or glycirenan or haemostatin or hemisine or hemostasin or hemostatin or hypernephrin or "isopto epinal" or l-adrenalin or levoepinephrine or levorenin* or methylaminoethanolcatechol or methylarterenol or mucidrina or myosthenine or nephridine or nieraline or paranephrin or posumin or "primatene mist" or renaglandin or renaleptine or renalina or renaline or renoform or renostypticin or renostyptin or scurenaline or simplene or soladren or sphygmogenin or supracapsulin or supranephrin or supranol or suprarenaline or suprarenin* or suprel or surenine or surrenine or sus-phrine or susphrine or takamina or tonogen or trenamist or twinject or vasoconstrictine or vasodrine or vasotonin or weradren or 51-43-4 or 55-31-2).tw.

55. dipivefrin.rn.

56. (dipivefrin* or dipivaloylepinephrine or Dipoquin or Glaucothil or Glaudrops or PMS-Dipivefrin or Propine or Diopine or ratio-Dipivefrin or Apo-Dipivefrin or 52365-63-6 or 56298-24-9).tw.

57. exp Adrenergic alpha-2 Receptor Agonists/

58. ((adrenergic adj 2 alpha* adj 3 agonist*) or (alpha* adj 2 adrenergic adj3 agent*) or (alpha* adj2 adrenergic receptor) or (alpha* adj2 adrenergic adj2 stimula*) or (alpha* adj2 adrenoceptor adj2 stimula*) or (alpha* adj3 agonist) or alpha* sympathicomimetic or noradrenalin agonist* or noradrenergic agonist* or noradrenergic receptor stimulating agent*).tw.

59. apraclonidine.rn.

60. (apraclonidin* or para-aminoclonidine or p-aminoclonidine or Iopidine or Iopimax or "ALO 2145" or "4 aminoclonidine" or aplonidine or clonidine or " 4 amino" or iopidine or lapidine or 66711-21-5).tw.

61. brimonidine.rn.

62. (brimonidine* or bromoxidine or ratio-Brimonidine or Alphagan or UK-14,308 or UK-14304 or UK-14304-18 or AGN-190342 or 59803-98-4).tw.

63. ((drug $\$$ or medic $\$$ or pharmacologic $\$)$ adj3 (treat $\$$ or therap $\$$ or intervent $\$))$.tw.

64. or/17-63

65. exp Drug Therapy, Combination/

66. (combination* or combine*).tw.

67. (polytherap* or multi-drug* or multiple drug*).tw.

68. (e-pilo* or 60996-13-6).tw.

69. (timpilo* or arutimol or betim or blocanol or cardina or chengrui or glauco or nyogel or timabak or timoftol or yesan or 26921-17-5).tw. 
70. Cosopt*.tw.

71. Azarga*.tw.

72. (Duotrav* or duo trav).tw.

73. Ganfort*.tw.

74. (Xalacom* or xalcom).tw.

75. Combigan*.tw.

76. Simbrinza*.tw.

77. (51 or 52$)$ and (27 or 28 or 53 or 54$)$

78. (19 or 20) and (33 or 34 or 35 or 36 or 39 or 40 or 41 or 42 or 43 or 44 or 61 or 62)

79. (33 or 34) and (61 or 62)

80. or/65-79

81. 16 and 64 and 80

82. 10 and 81

The search filter for trials at the beginning of the MEDLINE strategy is from the published paper by Glanville et al (Glanville 2006).

\section{Appendix 3. EMBASE.com search strategy}

\#1 'randomized controlled trial'/exp

\#2 'randomization'/exp

\#3 'double blind procedure'/exp

\#4 'single blind procedure'/exp

\#5 random*:ab,ti

\#6 \#1 OR \#2 OR \#3 OR \#4 OR \#5

\#7 'animal'/exp OR 'animal experiment'/exp

\#8 'human'/exp

\#9 \#7 AND \#8

\#10 \#7 NOT \#9

\#11 \#6 NOT \#10

\#12 'clinical trial'/exp

\#13 (clin* NEAR/3 trial*):ab,ti 


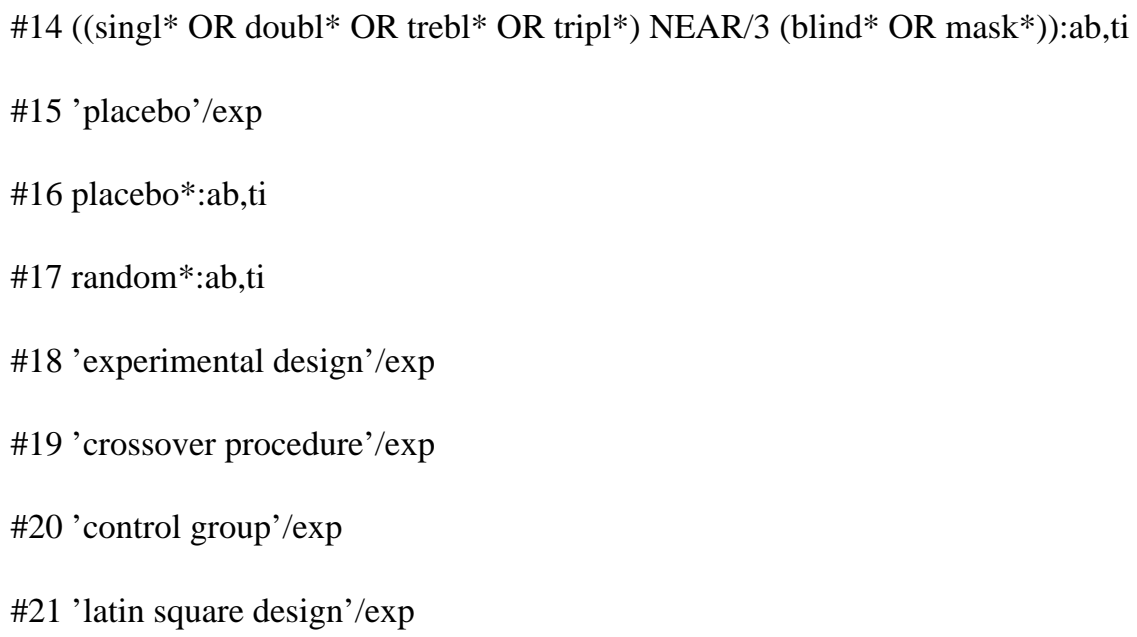


\#40 'beta adrenergic antagonist':ab,ti OR 'beta adrenergic blocker':ab,ti OR 'beta adrenergic blockers' :ab,ti OR 'beta adrenergic blocking agent':ab,ti OR 'beta adrenergic blocking drug':ab,ti OR 'beta adrenergic receptor antagonist':ab,ti OR 'beta adrenergic receptor blocker':ab,ti OR 'beta adrenoceptor antagonist':ab,ti OR 'beta adrenoceptor blocker':ab,ti OR 'beta adrenoceptor blocking agent': ab,ti OR 'beta adrenoceptor blocking drug':ab,ti OR 'beta adrenolytic':ab,ti OR 'beta adrenolytic agent':ab,ti OR 'beta antagonist':ab,ti OR 'beta antiadrenergic agent':ab,ti OR 'beta blocker':ab,ti OR 'beta blocking adrenergic agent':ab,ti OR 'beta blocking agent':ab,ti OR 'beta blocking drug':ab,ti OR 'beta receptor adrenergic blocking agent':ab,ti OR 'beta receptor blocker':ab,ti OR 'beta receptor blocking agent' :ab,ti OR 'beta sympathicolytic agent':ab,ti OR 'beta sympathicolytics':ab,ti OR 'beta sympatholytic agent':ab,ti OR 'betasympatholytic agent':ab,ti

\#41 'timolol'/exp

\#42 timolol*:ab,ti OR timoptic:ab,ti OR timoptol:ab,ti OR timacar:ab,ti OR '1 714465' :ab,ti OR 1714465:ab,ti OR 'mk 950':ab,ti OR mk950:ab,ti OR blocadren:ab,ti OR '26839 75 8 ':ab,ti OR 'apo timolol' :ab,ti OR 'apo timol':ab,ti OR 'apo timop':ab,ti OR 'apotimol':ab,ti OR apotimolol:ab,ti OR apotimop:ab,ti OR betimol:ab,ti OR istalol:ab,ti OR moducren:ab,ti OR nyolol:ab,ti OR ofal:ab,ti OR ofan:ab,ti OR optimol:ab,ti OR timolo:ab,ti OR titol:ab,ti \#43 'metipranolol'/exp

\#44 metipranolol*:ab,ti OR methypranol:ab,ti OR trimepranol:ab,ti OR disorat:ab,ti OR '22664 55 7':ab,ti OR 'beta ophtiole':ab,ti OR betalol:ab,ti OR betamann:ab,ti OR betamet:ab,ti OR betanol:ab,ti OR betanolol:ab,ti OR glauline:ab,ti OR 'normoglaucon mite':ab,ti OR ophtiole:ab,ti OR optipranolol:ab,ti

\#45 'carteolol'/exp

\#46 carteolol*:ab,ti OR opc1085:ab,ti OR '51781 06 7':ab,ti OR '51781 21 6':ab,ti OR arteolol:ab,ti OR arteoptic:ab,ti OR arteoptik: ab,ti OR caltamol:ab,ti OR calte:ab,ti OR carbonolol:ab,ti OR carteabak:ab,ti OR carteol:ab,ti OR cartrol:ab,ti OR 'catelon eye drop': ab,ti OR elebloc:ab,ti OR endak:ab,ti OR glauteolol:ab,ti OR karol:ab,ti OR karteol:ab,ti OR mikelan:ab,ti OR ocupress:ab,ti OR 'opc $1085^{\prime}$ :ab,ti OR stobol:ab,ti OR teoptic:ab,ti

\#47 'levobunolol'/exp

\#48 levobunolol*:ab,ti OR 'pms levobunolol':ab,ti OR pmslevobunolol:ab,ti OR 'ratio levobunolol':ab,ti OR ultracortenol:ab,ti OR vistagan:ab,ti OR 'w 6412a':ab,ti OR w6412a:ab,ti OR akbeta:ab,ti OR 'apo levobunolol' :ab,ti OR apolevobunolol:ab,ti OR betagan: ab,ti OR bunolol:ab,ti OR 'novo levobunolol' :ab,ti OR novolevobunolol:ab,ti OR w7000a:ab,ti OR '47141 42 4':ab,ti OR 'ak-beta': ab,ti OR 'ak beta':ab,ti OR betasite:ab,ti OR bunolgan:ab,ti OR gotensin:ab,ti OR 'w 7000a':ab,ti

\#49 'betaxolol'/exp 
\#50 betaxolol*:ab,ti OR kerlone:ab,ti OR kerlon:ab,ti OR oxodal:ab,ti OR sl75212:ab,ti OR alo140102:ab,ti OR betoptic:ab,ti OR betoptima:ab,ti OR '63659 18 7':ab,ti OR 'alo 1401 02':ab,ti OR betac:ab,ti OR betarun:ab,ti OR betasel:ab,ti OR betaxon:ab,ti OR betoquin:ab,ti OR kerlong:ab,ti OR levobetaxolol:ab,ti OR lokren:ab,ti OR optibet:ab,ti OR optipress:ab,ti OR 'sl 75212':ab,ti OR tonobexol:ab,ti OR '72424 72 7':ab,ti OR '93221 48 $8^{\prime}: \mathrm{ab}, \mathrm{ti}$

\#51 'carbonate dehydratase inhibitor'/exp

\#52 'carboanhydrase inhibitor':ab,ti OR 'carbonic anhydrase inhibitor':ab,ti OR 'carbonate dehydratase inhibitor':ab,ti OR 'carboanhydrase inhibitors':ab,ti OR 'carbonic anhydrase inhibitors':ab,ti OR 'carbonate dehydratase inhibitors':ab,ti

\#53 'acetazolamide'/exp

\#54 acetazolam*:ab,ti OR 'ak zol':ab,ti OR akzol:ab,ti OR apoacetazolamide:ab,ti OR diacarb:ab,ti OR diamox:ab,ti OR diuramide: ab,ti OR edemox:ab,ti OR glauconox:ab,ti OR glaupax:ab,ti OR 'huma zolamide':ab,ti OR humazolamide:ab,ti OR '59 66 5':ab,ti OR '1424 27 7':ab,ti OR acetadiazol:ab,ti OR acetamox:ab,ti OR 'acetazol amide':ab,ti OR acetazoleamide:ab,ti OR acetozolamine: ab,ti OR albox:ab,ti OR 'apo acetazolamide':ab,ti OR azetazolamide:ab,ti OR carbinib:ab,ti OR cidamex:ab,ti OR dazamide:ab,ti OR defiltran:ab,ti OR dehydratin:ab,ti OR diluran:ab,ti OR diomax:ab,ti OR 'diuriwas wassermann barcelona':ab,ti OR diutazol:ab,ti OR eumicton:ab,ti OR fonurit:ab,ti OR genephamide:ab,ti OR glaucomed:ab,ti OR glaucomide:ab,ti OR ledamox:ab,ti OR lediamox: ab,ti OR ledimox:ab,ti OR natrionex:ab,ti OR nephramid:ab,ti OR novozolamide:ab,ti OR storzolamide:ab,ti OR ulcosilvanil:ab,ti OR ulcosylvanil:ab,ti \#55 brinzolamide*:ab,ti OR azopt:ab,ti OR '138890 62 7':ab,ti OR 'al 4862':ab,ti OR al4862:ab,ti OR azoptic:ab,ti

\#56 dorzolamide*:ab,ti OR trusopt:ab,ti OR '130693 82 2':ab,ti OR biodrop:ab,ti OR '1 671 152':ab,ti OR '1 671152':ab,ti OR 'mk 13507':ab,ti OR 'mk 0507':ab,ti OR 'mk 507':ab,ti

\#57 'latanoprost'/exp

\#58 latanoprost*:ab,ti OR phxa41:ab,ti OR xalatan:ab,ti OR phxa34:ab,ti OR '130209 82 4 ':ab,ti OR loutenor:ab,ti

\#59 'travoprost'/exp

\#60 travoprost*:ab,ti OR travatan:ab,ti OR 'al 6221':ab,ti OR al6221:ab,ti OR '157283 68

6 ':ab,ti OR 'fluprostenol isopropyl ester': ab,ti OR 'travatan z':ab,ti

\#61 'bimatoprost'/exp

\#62 bimatoprost*:ab,ti OR latisse:ab,ti OR lumigan:ab,ti OR agn192024:ab,ti OR 'agn

192024':ab,ti OR '155206 00 1':ab,ti

\#63 'unoprostone isopropyl ester'/exp 
\#64 unoprostone*:ab,ti OR rescula:ab,ti OR eescula:ab,ti OR '69553 75 9':ab,ti OR '120373 24 2':ab,ti OR 'uf 021':ab,ti OR uf021: ab,ti

\#65 'brimonidine'/exp

\#66 brimonidine*:ab,ti OR bromoxidine:ab,ti OR 'ratio brimonidine':ab,ti OR alphagan:ab,ti OR 'uk 14308':ab,ti OR '59803 98 4': ab,ti OR 'agn 190342':ab,ti OR agn190342:ab,ti OR 'alphagan-p':ab,ti OR 'uk 14304':ab,ti OR 'uk 14304 18':ab,ti OR 'uk14304': ab,ti OR 'uk14304 18':ab,ti OR uk1430418:ab,ti

\#67' antihypertensive agent'/exp

\#68 antihypertensive*:ab,ti OR 'anti hypertensives':ab,ti OR 'anti hypertensive':ab,ti \#69 'pilocarpine'/exp

\#70 pilocarpin*:ab,ti OR isoptocarpine:ab,ti OR salagen:ab,ti OR isopilocarpine:ab,ti OR ocusert:ab,ti OR adsorbocarpine:ab,ti OR akarpine:ab,ti OR almocarpine:ab,ti OR asthenopin:ab,ti OR glaucocarpine:ab,ti OR 'isopto carpine':ab,ti OR isoptopilocarpine:ab,ti OR liocarpina:ab,ti OR miocarpine:ab,ti OR 'ocu carpine':ab,ti OR ocucarpine:ab,ti OR pilagan:ab,ti OR pilasite:ab,ti OR pilocar: ab,ti OR pilocarpin:ab,ti OR pilocarpol:ab,ti OR pilofrin:ab,ti OR pilogel:ab,ti OR piloheptine:ab,ti OR pilomann:ab,ti OR pilomin: ab,ti OR pilomiotin:ab,ti OR pilopine:ab,ti OR pilostat:ab,ti OR pilosyst:ab,ti OR pilotonina:ab,ti OR sanpilo:ab,ti OR 'sno pilo': ab,ti OR spersacarpine:ab,ti OR vistacarpin:ab,ti OR vitacarpine:ab,ti OR zhenrui:ab,ti OR '148 72 1':ab,ti OR '54 71 7':ab,ti OR '92 13 7':ab,ti

\#71 'adrenalin'/exp

\#72 epinephrine*:ab,ti OR adrenalin*:ab,ti OR 'medihaler epi' :ab,ti OR epitrate:ab,ti OR lyophrin:ab,ti OR epifrin:ab,ti OR adnephrin*:ab,ti OR adrenamine:ab,ti OR adrenapax:ab,ti OR adrenazin:ab,ti OR adrenine:ab,ti OR adrin:ab,ti OR adrine:ab,ti OR advaradin:ab,ti OR anapen:ab,ti OR asthmahaler:ab,ti OR balmadren:ab,ti OR biorenine:ab,ti OR bosmin:ab,ti OR chelafrin:ab,ti OR dylephrin:ab,ti OR epimephrine:ab,ti OR epinefrina:ab,ti OR epinephran:ab,ti OR epinephrin*:ab,ti OR epipen:ab,ti OR epirenamine: ab,ti OR epirenan:ab,ti OR exadrin:ab,ti OR glaucon:ab,ti OR glaucosan:ab,ti OR glaufrin:ab,ti OR glycirenan:ab,ti OR haemostatin: ab,ti OR hemisine:ab,ti OR hemostasin:ab,ti OR hemostatin:ab,ti OR hypernephrin:ab,ti OR 'isopto epinal' :ab,ti OR '1 adrenalin':ab,ti OR levoepinephrine:ab,ti OR levorenin*:ab,ti OR methylaminoethanolcatechol:ab,ti OR methylarterenol:ab,ti OR mucidrina:ab,ti OR myosthenine:ab,ti OR nephridine:ab,ti OR nieraline:ab,ti OR paranephrin:ab,ti OR posumin:ab,ti OR 'primatene mist':ab,ti OR renaglandin:ab,ti OR renaleptine:ab,ti OR renalina:ab,ti OR renaline:ab,ti OR renoform:ab,ti OR renostypticin:ab,ti OR renostyptin: ab,ti OR scurenaline:ab,ti OR simplene:ab,ti OR soladren:ab,ti OR sphygmogenin:ab,ti OR supracapsulin:ab,ti OR supranephrin: ab,ti OR supranol:ab,ti OR suprarenaline:ab,ti OR suprarenin*:ab,ti OR suprel:ab,ti OR surenine:ab,ti OR surrenine:ab,ti OR 'sus phrine':ab,ti OR susphrine:ab,ti OR takamina:ab,ti OR tonogen:ab,ti OR trenamist:ab,ti OR twinject:ab,ti OR vasoconstrictine:ab,ti OR vasodrine:ab,ti OR vasotonin:ab,ti OR weradren:ab,ti OR '51 43 4':ab,ti OR '55 31 2':ab,ti 
\#73 dipivefrin*:ab,ti

\#74 dipivefrin*:ab,ti OR dipivaloylepinephrine:ab,ti OR dipoquin:ab,ti OR glaucothil:ab,ti OR glaudrops:ab,ti OR 'pms dipivefrin': ab,ti OR propine:ab,ti OR diopine:ab,ti OR 'ratio dipivefrin':ab,ti OR 'apo dipivefrin' :ab,ti OR '52365 63 6':ab,ti OR '56298 24 9': ab,ti

\#75 'alpha 2 adrenergic receptor stimulating agent'/exp

\#76 'adrenergic alpha agonists' :ab,ti OR 'alpha adrenergic agent':ab,ti OR 'alpha adrenergic agonist':ab,ti OR 'alpha adrenergic receptor agent' ab,ti OR 'alpha adrenergic receptor agonist' :ab,ti OR 'alpha adrenergic receptor stimulant':ab,ti OR 'alpha adrenergic receptor stimulator':ab,ti OR 'alpha adrenergic stimulant' ab,ti OR 'alpha adrenergic stimulating agent':ab,ti OR 'alpha adrenergic stimulator': ab,ti OR 'alpha adrenoceptor agonist':ab,ti OR 'alpha adrenoceptor stimulant':ab,ti OR 'alpha adrenoceptor stimulating agent':ab,ti OR 'alpha adrenoceptor stimulator' :ab,ti OR 'alpha agonist':ab,ti OR 'alpha sympathicomimetic':ab,ti OR 'noradrenalin agonist':ab,ti OR 'noradrenergic agonist':ab,ti OR 'noradrenergic receptor stimulating agent':ab,ti

\#77 apraclonidin*:ab,ti

\#78 apraclonidin*:ab,ti OR 'para aminoclonidine':ab,ti OR 'p aminoclonidine':ab,ti OR iopimax:ab,ti OR 'alo 2145' :ab,ti OR '4 aminoclonidine':ab,ti OR aplonidine:ab,ti OR clonidine:ab,ti OR '4 amino' :ab,ti OR iopidine:ab,ti OR lapidine:ab,ti OR '66711 21 5':ab,ti \#79 'tafluprost'/exp \#80 tafluprost*:ab,ti OR 'afp 168':ab,ti OR afp168:ab,ti OR 'de 085':ab,ti OR de085:ab,ti OR taflotan:ab,ti OR tapros:ab,ti OR zioptan:ab,ti OR '209860 87 7':ab,ti \#81 ((drug* OR medic* OR pharmacologic*) NEAR/3 (treat* OR therap* OR intervent*)):ab,ti

\#82 \#39 OR \#40 OR \#41 OR \#42 OR \#43 OR \#44 OR \#45 OR \#46 OR \#47 OR \#48 OR \#49 OR \#50 OR \#51 OR \#52 OR \#53 OR \#54 OR \#55 OR \#56 OR \#57 OR \#58 OR \#59 OR \#60 OR \#61 OR \#62 OR \#63 OR \#64 OR \#65 OR \#66 OR \#67 OR \#68 OR \#69 OR \#70 OR \#71 OR \#72 OR \#73 OR \#74 OR \#75 OR \#76 OR \#77 OR \#78 OR \#79 OR \#80 OR \#81

\#83 'drug combination'/exp

\#84 combination*:ab,ti OR combine*:ab,ti \#85 polytherap*:ab,ti OR 'multi drug':ab,ti OR 'multi drugs':ab,ti OR multiple:ab,ti AND drug*:ab,ti

\#86 'adrenalin plus pilocarpine'/exp

\#87'e pilo':ab,ti OR '60996 13 6':ab,ti

\#88 'timolol maleate'/exp 
\#89 timpilo*:ab,ti OR arutimol:ab,ti OR betim:ab,ti OR blocanol:ab,ti OR cardina:ab,ti OR chengrui:ab,ti OR glauco:ab,ti OR nyogel: ab,ti OR timabak:ab,ti OR timoftol:ab,ti OR yesan:ab,ti OR '26921 17 5':ab,ti

\#90 'dorzolamide plus timolol'/exp

\#91 cosopt*:ab,ti

\#92 'brinzolamide plus timolol'/exp

\#93 azarga*:ab,ti

\#94 'timolol plus travoprost'/exp

\#95 duotrav*:ab,ti OR 'duo trav':ab,ti

\#96 'bimatoprost plus timolol'/exp

\#97 ganfort*:ab,ti

\#98 'latanoprost plus timolol'/exp

\#99 xalacom*:ab,ti OR xalcom:ab,ti

\#100 'brimonidine plus timolol'/exp

\#101 combigan*:ab,ti

\#102 'brimonidine plus brinzolamide'/exp

\#103 simbrinza*:ab,ti

\#104 \#83 OR \#84 OR \#85 OR \#86 OR \#87 OR \#88 OR \#89 OR \#90 OR \#91 OR \#92 OR \#93 OR \#94 OR \#95 OR \#96 OR \# 97 OR \#98 OR \#99 OR \#100 OR \#101 OR \#102 OR \#103

\#105 \#38 AND \#82 AND \#104

\#106 \#32 AND \#105

\section{Appendix 4. PubMed search strategy}

1. ((randomized controlled trial[pt]) OR (controlled clinical trial[pt]) OR (randomised[tiab] OR randomized[tiab]) OR (placebo[tiab]) OR (drug therapy[sh]) OR (randomly[tiab]) OR (trial[tiab]) OR (groups[tiab])) NOT (animals[mh] NOT humans[mh])

2. (open[tw] AND angle[tw] AND glaucoma*[tw]) NOT Medline[sb]

3. (POAG[tw] OR OHT[tw]) NOT Medline[sb] 
4. (( (increase*[tw] OR elevat*[tw] OR high*[tw]) AND (ocular[tw] OR intraocular[tw])) AND pressure[tw]) NOT Medline[sb]

5. \#2 OR \#3 OR \#4

6. ((Adrenergic[tw] AND beta*[tw] AND Block*[tw]) OR (Adrenergic[tw] AND beta*[tw] AND Antagonist*[tw]) OR (beta*[tw] AND antagonist*[tw]) OR (beta*[tw] AND blocker*[tw]) OR (beta*[tw] AND blocking[tw] AND agent*[tw]) OR (beta[tw] AND blocking[tw] AND drug*[tw]) OR beta sympathicolytic*[tw] OR beta sympatholytic*[tw]) NOT Medline[sb]

7. (Timolol*[tw] OR Timoptic[tw] OR Timoptol[tw] OR Timacar[tw] OR L-714,465[tw] OR L714465[tw] OR MK-950[tw] OR MK950[tw] OR Optimol[tw] OR Blocadren[tw] OR 26839-75-8[tw]) NOT Medline[sb]

8. (Metipranolol*[tw] OR Methypranol[tw] OR Trimepranol[tw] OR Disorat[tw] OR 22664-55-7[tw]) NOT Medline[sb]

9. (Carteolol*[tw] OR OPC-1085[tw] OR OPC1085[tw] OR 51781-06-7[tw]) NOT Medline[sb]

10. (Levobunolol*[tw] OR PMS-Levobunolol[tw] OR PMSLevobunolol[tw] OR ratioLevobunolol[tw] OR Ultracortenol[tw] OR Vistagan[tw] OR W-6412A[tw] OR W6412A[tw] OR AKBeta[tw] OR Apo-Levobunolol[tw] OR ApoLevobunolol[tw] OR Beta-gan[tw] OR Bunolol[tw] OR Novo-Levobunolol[tw] OR NovoLevobunolol[tw] OR W-7000A[tw] OR W7000A[tw] OR 47141-42-4[tw]) NOT Medline[sb]

11. (Betaxolol*[tw] OR Kerlone[tw] OR Kerlon[tw] OR Oxodal[tw] OR SL-75212[tw] OR SL75212[tw] OR ALO-1401-02[tw] OR ALO140102[tw] OR Betoptic[tw] OR Betoptima[tw] OR 63659-18-7[tw]) NOT Medline[sb]

12. ((Carbonic[tw] AND Anhydrase[tw] AND Inhibitor*[tw]) OR (Carbonate[tw] AND Dehydratase[tw] AND Inhibitor*[tw]) OR (Carboxyanhydrase[tw] AND Inhibitor*[tw])) NOT Medline[sb]

13. (Acetazolam*[tw] OR Ak-Zol[tw] OR AkZol[tw] OR Apo-Acetazolamide[tw] OR ApoAcetazolamide[tw] OR Diacarb[tw] OR Diamox[tw] OR Diuramide[tw] OR Defiltran[tw] OR Edemox[tw] OR Glauconox[tw] OR Glaupax[tw] OR HumaZolamide[tw] OR HumaZolamide[tw] OR Acetadiazol[tw] OR azetazolamide*[tw] OR 59-66-5[tw]) NOT Medline[sb]

14. (Brinzolamide*[tw] OR Azopt[tw] OR 138890-62-7[tw]) NOT Medline[sb]

15. (Dorzolamide*[tw] OR MK-507[tw] OR Trusopt[tw] OR L-671152[tw] OR 130693-82-2[tw]) NOT Medline[sb]

16. ("Synthetic Prostaglandins" [tw] OR "PG Analogs" [tw] OR "Prostaglandin Analogues"[tw] OR "Prostaglandin Analogs"[tw] OR dimethylprostaglandin[tw] OR methylprostaglandin[tw] OR “prostaglandin 1"[tw]) NOT Medline[sb] 
17. (latanoprost*[tw] OR PHXA41[tw] OR Xalatan[tw] OR PhXA34[tw] OR 130209-82-4[tw]) NOT Medline[sb]

18. (travoprost*[tw] OR Travatan[tw] OR AL-6221[tw] OR AL6221[tw] OR 157283-68-6[tw]) NOT Medline[sb]

19. (bimatoprost*[tw] OR latisse[tw] OR Lumigan[tw] OR AGN192024[tw]) NOT Medline[sb]

20. (unoprostone*[tw] OR UF-021[tw] OR Rescula[tw] OR Eescula[tw] OR 69553-75-9[tw]) NOT Medline[sb]

21. (tafluprost*[tw] OR “AFP 168"[tw] OR AFP168[tw] OR “de 085"[tw] OR de085 [tw] OR taflotan[tw] OR tapros [tw] OR zioptan[tw] OR 209860-87-7[tw]) NOT Medline[sb]

22. (antihypertensive*[tw] OR "Anti Hypertensives" $[\mathrm{tw}]$ OR "Anti Hypertensive" $[\mathrm{tw}]$ ) NOT Medline[sb]

23. (Pilocarpin*[tw] OR Isoptocarpine[tw] OR Salagen[tw] OR Isopilocarpine[tw] OR Ocusert[tw] OR adsorbocarpine[tw] OR akarpine[tw] OR almocarpine[tw] OR asthenopin[tw] OR glaucocarpine[tw] OR "isopto carpine"[tw] OR isoptopilocarpine[tw] OR liocarpina[tw] OR miocarpine[tw] OR ocu-carpine[tw] OR ocucarpine[tw] OR pilagan[tw] OR pilasite[tw] OR pilocar[tw] OR pilocarpol[tw] OR pilofrin[tw] OR pilogel[tw] OR piloheptine[tw] OR pilomann[tw] OR pilomin[tw] OR pilomiotin[tw] OR pilopine[tw] OR pilostat[tw] OR pilosyst[tw] OR pilotonina[tw] OR sanpilo[tw] OR "sno pilo"[tw] OR spersacarpine[tw] OR vistacarpin[tw] OR vitacarpine[tw] OR zhenrui[tw] OR 148-72-1[tw] OR 54-71-7[tw] OR 92-13-7[tw]) NOT Medline[sb]

24. (epinephrine*[tw] OR adrenalin*[tw] OR Medihaler-Epi[tw] OR Epitrate[tw] OR Lyophrin[tw] OR Epifrin[tw] OR Adnephrin*[tw] OR adrenamine[tw] OR adrenapax [tw] OR adrenazin[tw] OR adrenine[tw] OR adrin[tw] OR adrine[tw] OR advaradin[tw] OR anapen[tw] OR asthmahaler[tw] OR balmadren[tw] OR biorenine[tw] OR bosmin[tw] OR chelafrin[tw] OR dylephrin[tw] OR epimephrine[tw] OR epinefrina[tw] OR epinephran[tw] OR epinephrin*[tw] OR epipen[tw] OR epirenamine[tw] OR epirenan[tw] OR exadrin[tw] OR glaucon[tw] OR glaucosan[tw] OR glaufrin[tw] OR glycirenan[tw] OR haemostatin[tw] OR hemisine[tw] OR hemostasin[tw] OR hemostatin[tw] OR hypernephrin[tw] OR "isopto epinal" [tw] OR l-adrenalin[tw] OR levoepinephrine[tw] OR levorenin*[tw] OR methylaminoethanolcatechol[tw] OR methylarterenol[tw] OR mucidrina[tw] OR myosthe-nine[tw] OR nephridine[tw] OR nieraline[tw] OR paranephrin[tw] OR posumin[tw] OR "primatene mist" [tw] OR renaglandin[tw] OR renaleptine[tw] OR renalina[tw] OR renaline[tw] OR renoform[tw] OR renostypticin[tw] OR renostyptin[tw] OR scurenaline[tw] OR simplene[tw] OR soladren[tw] OR sphygmogenin[tw] OR supracapsulin[tw] OR supranephrin[tw] OR supranol[tw] OR suprarenaline [tw] OR suprarenin*[tw] OR suprel[tw] OR surenine[tw] OR surrenine[tw] OR sus-phrine[tw] OR susphrine[tw] OR takamina[tw] OR tonogen[tw] OR trenamist[tw] OR twinject[tw] OR vasoconstrictine[tw] OR 
vasodrine[tw] OR vasotonin[tw] OR weradren[tw] OR 51-43-4[tw] OR 55-31-2[tw]) NOT Medline[sb]

25. (dipivefrin*[tw] OR dipivaloylepinephrine[tw] OR Dipoquin[tw] OR Glaucothil[tw] OR Glaudrops[tw] OR PMS-Dipivefrin[tw] OR Propine[tw] OR Diopine[tw] OR ratio-Dipivefrin[tw] OR Apo-Dipivefrin[tw] OR 52365-63-6[tw] OR 56298-24-9[tw]) NOT Medline[sb]

26. ((adrenergic[tw] AND alpha*[tw] AND agonist*[tw]) OR (alpha*[tw] AND adrenergic[tw] AND agent*[tw]) OR (alpha*[tw] AND adrenergic[tw] AND receptor[tw]) OR (alpha*[tw] AND adrenergic[tw] AND stimula*[tw]) OR (alpha*[tw] AND adrenoceptor[tw] AND stimula*[tw]) OR (alpha*[tw] AND agonist[tw]) OR alpha sympathicomimetic[tw] OR noradrenalin agonist*[tw] OR noradrenergic agonist*[tw] OR noradrenergic receptor stimulating agent*[tw]) NOT Medline[sb]

27. (apraclonidin*[tw] OR para-aminoclonidine[tw] OR p-aminoclonidine[tw] OR Iopidine[tw] OR Iopimax[tw] OR “ALO 2145”[tw] OR “4 aminoclonidine"[tw] OR aplonidine[tw] OR clonidine[tw] OR “4 amino"[tw] OR iopidine[tw] OR lapidine[tw] OR 66711-21-5[tw]) NOT Medline[sb]

28. (brimonidine*[tw] OR bromoxidine[tw] OR ratio-Brimonidine[tw] OR Alphagan[tw] OR UK-14,308[tw] OR UK-14304[tw] OR UK-14304-18[tw] OR AGN-190342[tw] OR 59803-98-4[tw]) NOT Medline[sb]

29. ((drug*[tw] OR medic*[tw] OR pharmacologic*[tw]) AND (treat*[tw] OR therap*[tw] OR intervent*[tw])) NOT Medline[sb]

30. \#6 OR \#7 OR \#8 OR \#9 OR \#10 OR \#11 OR \#12 OR \#13 OR \#14 OR \#15 OR \#16 OR \#17 OR \#18 OR \#19 OR \#20 OR \# 21 OR \#22 OR \#23 OR \#24 OR \#25 OR \#26 OR \#27 OR \#28 OR \#29

31. (combination*[tw] OR combine*[tw]) NOT Medline[sb]

32. (polytherap*[tw] OR multi-drug*[tw] OR multiple drug*[tw]) NOT Medline[sb]

33. (e-pilo*[tw] OR 60996-13-6[tw]) NOT Medline[sb]

34. (timpilo*[tw] OR arutimol[tw] OR betim[tw] OR blocanol[tw] OR cardina[tw] OR chengrui[tw] OR glauco[tw] OR nyogel[tw] OR timabak[tw] OR timoftol[tw] OR yesan[tw] OR 26921-17-5[tw]) NOT Medline[sb]

35. Cosopt*[tw] NOT Medline[sb]

36. Azarga*[tw] NOT Medline[sb]

37. (Duotrav*[tw] OR duo trav[tw]) NOT Medline[sb]

38. Ganfort*[tw] NOT Medline[sb]

39. (Xalacom*[tw] OR xalcom[tw]) NOT Medline[sb]

40. Combigan*[tw] NOT Medline[sb]

41. Simbrinza*[tw] NOT Medline[sb] 

42. \#31 OR \#32 OR \#33 OR \#34 OR \#35 OR \#36 OR \#37 OR \#38 OR \#39 OR \#40 OR \#41

43. \#5 AND \#30 AND \#42

44. \#1 AND \#43

\section{Appendix 5. meta Register of Controlled Trials search strategy}

(“Primary open angle glaucoma” OR “ocular hypertension”)

\section{Appendix 6. ClinicalTrials.gov search strategy}

Condition: ("Primary open angle glaucoma" OR "ocular hypertension

\section{Appendix 7. ICTRP search strategy}

Condition: ("Primary open angle glaucoma“ OR "ocular hypertension“)

\section{REFERENCES}

American Academy of Ophthalmology (AAO). Primary angle closure glaucoma. Preferred Practice Patterns Guidelines. American Academy of Opthalmology; San Francisco, CA: 2010.

Baratz KH, Nau CB, Winter EJ, McLaren JW, Hodge DO, Herman DC, et al. Effects of glaucoma medications on corneal endothelium, keratocytes, and subbasal nerves among participants in the ocular hypertension treatment study. Cornea. 2006; 25(9):1046-52. [PubMed: 17133051]

Brandt JD, Beiser JA, Kass MA, Gordon MO. Central corneal thickness in the Ocular Hypertension Treatment Study (OHTS). Ophthalmology. 2001; 108(10):1779-88. [PubMed: 11581049]

Bron AM, Emmerich KH. Latanoprost versus combined timolol and dorzolamide. Survey of Ophthalmology. 2002; 47(Suppl 1):S148-54. [PubMed: 12204712]

Burr J, Azuara-Blanco A, Avenell A, Tuulonen A. Medical versus surgical interventions for open angle glaucoma. Cochrane Database of Systematic Reviews. 2012; (Issue 9) [DOI: 10.1002/14651858.CD004399.pub3].

Chaimani A, Higgins JP, Mavridis D, Spyridonos P, Salanti G. Graphical tools for network metaanalysis in STATA. PLoS One. 2013; 8(10):e76654. [PubMed: 24098547]

Chauhan BC, Mikelberg FS, Artes PH, Balazsi AG, LeBlanc RP, Lesk MR, et al. Canadian glaucoma study group. Archives of Ophthalmology. 2010; 128(10):1249-55. [PubMed: 20696979]

de Voogd S, Ikram MK, Wolfs RC, Jansonius NM, Hofman A, de Jong PT. Incidence of open-angle glaucoma in a general elderly population: the Rotterdam Study. Ophthalmology. 2005; 112(9): 1487-93. [PubMed: 16039716]

Dias S, Welton NJ, Sutton AJ, Caldwell DM, Lu G, Ades AE. Evidence synthesis for decision making 4: inconsistency in networks of evidence based on randomized controlled trials. Medical Decision Making. 2013; 33:641-56. [PubMed: 23804508]

Djafari F, Lesk MR, Harasymowycz PJ, Desjardins D, Lachaine J. Determinants of adherence to glaucoma medical therapy in a long-term patient population. Journal of Glaucoma. 2009; 18(3): 238-43. [PubMed: 19295380]

Everitt DE, Avorn J. Systemic effects of medications used to treat glaucoma. Annals of Internal Medicine. 1990; 112(2):120-5. [PubMed: 1967209]

Fechtner RD, Realini T. Fixed combinations of topical glaucoma medications. Current Opinion in Ophthalmology. 2004; 15(2):132-5. [PubMed: 15021225]

Gordon MO, Beiser JA, Brandt JD, Heuer DK, Higginbotham EJ, Johnson CA, et al. The ocular hypertension treatment study: baseline factors that predict the onset of primary open-angle glaucoma. Archives of Ophthalmology. 2002; 120(6):714-20. [PubMed: 12049575] 
Higgins, JPT.; Altman, DG.; Sterne, JAC. Chapter 8: Assessing risk of bias in included studies.. In: Higgins, JPT.; Green, S., editors. Cochrane Handbook for Systematic Reviews of Interventions Version 5.1.0 (updated March 2011). The Cochrane Collaboration; 2011. Available from www.cochrane-handbook.org.

Hurvitz LM, Kaufman PL, Robin AL, Weinreb RN, Crawford K, Shaw B. New developments in the drug treatment of glaucoma. Drugs. 1991; 41(4):514-32. [PubMed: 1711957]

Jackson D, Barrett JK, Rice S, White IR, Higgins JP. A design-by-treatment interaction model for network meta-analysis with random inconsistency effects. Statistics in Medicine. 2014; 33(21): 3639-57. [PubMed: 24777711]

Kass MA, Heuer DK, Higginbotham EJ, Johnson CA, Keltner JL, Miller JP, et al. The Ocular Hypertension Treatment Study: a randomized trial determines that topical ocular hypotensive medication delays or prevents the onset of primary open-angle glaucoma. Archives of Ophthalmology. 2002; 120(6):701-13. [PubMed: 12049574]

King A, Azuara-Blanco A, Tuulonen A. Glaucoma. BMJ. 2013; 346:f3518. [PubMed: 23757737]

Leske MC, Heijl A, Hussein M, Bengtsson B, Hyman L, Komaroff E. Factors for glaucoma progression and the effect of treatment: the early manifest glaucoma trial. Archives of Ophthalmology. 2003; 121(1):48-56. [PubMed: 12523884]

Leske MC, Wu SY, Honkanen R, Nemesure B, Schachat A, Hyman L, et al. Nine-year incidence of open-angle glaucoma in the Barbados Eye Studies. Ophthalmology. 2007; 114(6):1058-64. [PubMed: 17397925]

Li T, Puhan M, Vedula S, Singh S, Dickersin K, for the Ad Hoc Network Meta-analysis Methods Meeting Working Group. Network meta-analysis - highly attractive and more methodological research is needed. BMC Medicine. 2011; 9(1):79. [PubMed: 21707969]

Marcus MW, de Vries MM, Junoy Montolio FG, Jansonius NM. Myopia as a risk factor for openangle glaucoma: a systematic review and meta-analysis. Ophthalmology. 2011; 118(10):1989-94. [PubMed: 21684603]

Puhan MA, Schünemann HJ, Murad MH, Li T, Brignardello-Petersen R, Singh JA, et al. A GRADE Working Group approach for rating the quality of treatment effect estimates from network metaanalysis. BMJ. 2014; 349:g5630. [PubMed: 25252733]

Quigley HA, Broman AT. The number of people with glaucoma worldwide in 2010 and 2020. British Journal of Ophthalmology. 2006; 90(3):262-7. [PubMed: 16488940]

Quigley HA. Glaucoma. Lancet. 2011; 377(9774):1367-77. [PubMed: 21453963]

The Nordic Cochrane Centre. The Cochrane Collaboration. Review Manager (RevMan). 5.3. The Nordic Cochrane Centre, The Cochrane Collaboration; Copenhagen: 2014.

Rolim de Moura C, Paranhos A Jr, Wormald R. Laser trabeculoplasty for open angle glaucoma. Cochrane Database of Systematic Reviews. 2007; (Issue 4) [DOI: 10.1002/ 14651858.CD003919.pub2].

Salanti G, Ades AE, Ioannidis JP. Graphical methods and numerical summaries for presenting results from multiple-treatment meta-analysis: an overview and tutorial. Journal of Clinical Epidemiology. 2011; 64(2):163-71. [PubMed: 20688472]

Salanti G. Indirect and mixed-treatment comparison, network, or multiple-treatments meta-analysis: many names, many benefits, many concerns for the next generation evidence synthesis tool. Research Synthesis Methods. 2012; 3(2):80-97.

Schünemann, HJ.; Oxman, AD.; Higgins, JPT.; Vist, GE.; Glasziou, P.; Guyatt, GH. Chapter 11: Presenting results and 'Summary of findings' tables.. In: Higgins, JPT.; Green, S., editors. Cochrane Handbook for Systematic Reviews of Interventions Version 5.1.0 (updated March 2011). The Cochrane Collaboration; 2011. Available from www.cochrane-handbook.org.

Schünemann, HJ.; Oxman, AD.; Vist, GE.; Higgins, JPT.; Deeks, JJ.; Glasziou, P., et al. Chapter 12: Interpreting results and drawing conclusions.. In: Higgins, JPT.; Green, S., editors. Cochrane Handbook for Systematic Reviews of Interventions Version 5.1.0 (updated March 2011). The Cochrane Collaboration; 2011. Available from www.cochrane-handbook.org.

Shields MB. Normal-tension glaucoma: is it different from primary open-angle glaucoma?. Current Opinion in Ophthalmology. 2008; 19(2):85-8. [PubMed: 18301279] 
Sleath B, Robin AL, Covert D, Byrd JE, Tudor G, Svarstad B. Patient reported behavior and problems in using glaucoma medications. Ophthalmology. 2006; 113(3):431-6. [PubMed: 16458967]

Sommer A, Tielsch JM, Katz J, Quigley HA, Gottsch JD, Javitt JC, et al. Racial differences in the cause-specific prevalence of blindness in east Baltimore. New England Journal of Medicine. 1991; 325(20):1412-7. [PubMed: 1922252]

Sommer A, Tielsch JM, Katz J, Quigley HA, Gottsch JD, Javitt J, et al. Relationship between intraocular pressure and primary open-angle glaucoma among white and black Americans. The Baltimore Eye Survey. Archives of Ophthalmology. 1991; 109(8):1092.

Sommer A. Ocular hypertension and normal-tension glaucoma: time for banishment and burial. Archives of Ophthalmology. 2011; 129(6):785-7. [PubMed: 21670346]

Stata Statistical Software: Release 13. StataCorp LP; College Station, TX: 2013. College Station, TX: StataCorp LP. StataCorp.

Varma R, Ying-Lai M, Francis BA, Nguyen BB, Deneen J, Wilson MR, et al. Prevalence of openangle glaucoma and ocular hypertension in Latinos: the Los Angeles Latino Eye Study. Ophthalmology. 2004; 111(8):1439-48. [PubMed: 15288969]

Varma R, Wang D, Wu C, Francis BA, Nguyen BB, Chopra V, et al. Four-year incidence of openangle glaucoma and ocular hypertension: the Los Angeles Latino Eye Study. American Journal of Ophthalmology. 2012; 154(2):315-25. [PubMed: 22541649]

Vass C, Hirn C, Sycha T, Findl O, Bauer P, Schmetterer L. Medical interventions for primary open angle glaucoma and ocular hypertension. Cochrane Database of Systematic Reviews. 2007; (Issue 4) [DOI: 10.1002/ 14651858.CD003167.pub3].

Waterman H, Evans JR, Gray TA, Henson D, Harper R. Interventions for improving adherence to ocular hypotensive therapy. Cochrane Database of Systematic Reviews. 2013; (Issue 4) [DOI: 10.1002/14651858.CD006132.pub3].

Webers CA, van der Valk R, Schouten JS, Zeegers MP, Prins MH, Hendrikse F. Intraocular pressurelowering effect of adding dorzolamide or latanoprost to timolol: a meta-analysis of randomized clinical trials. Ophthalmology. 2007; 114(1):40-6. [PubMed: 17070584]

Webers CA, Beckers HJ, Nujits RM, Schouten JS. Pharmacological management of primary openangle glaucoma: second-line options and beyond. Drugs Aging. 2008; 25(9):729-59. [PubMed: 18729546]

Weinreb RN, Khaw PT. Primary open-angle glaucoma. Lancet. 2004; 363(9422):1711-20. [PubMed: 15158634]

White IR. Multivariate random-effects meta-regression: updates to mvmeta. The STATA Journal. 2011; 11(2):255-70.

White IR, Barrett JK, Jackson D, Higgins JPT. Consistency and inconsistency in network metaanalysis: model estimation using multivariate meta-regression. Research Synthesis Methods. 2012; 3(2):111-25. *Indicates the major publication for the study. 